\title{
Efecto de la poda temprana de brotes laterales en el inicio de la floración de papaya Tainung 1
}

\section{Effect to early pruning of lateral shoots at the beginning of the papaya Tainung 1 flowering}

\author{
Jeronimo Hoyos ${ }^{1}$, Alejandro Hurtado-Salazar ${ }^{2 *}$
}

Recibido para publicación: Noviembre 2 de 2016 - Aceptado para publicación: Mayo 18 de 2017

\begin{abstract}
RESUMEN
El cultivo de papaya se maneja principalmente basado en el conocimiento tradicional de los agricultores, debido a que la investigación en aspectos fisiológicos es escasa y no existe información científica acerca del efecto de la poda temprana en la floración. La poda de brotes laterales generalmente se realizan entre los 55 y 70 días después del trasplante, cuando surge el primer botón floral, perdiendo fotoasimilados en los brotes en estos primeros días después del trasplante. El objetivo del estudio fue evaluar el efecto de la poda temprana al inicio de la floración de la papaya Tainung 1 . El estudio se realizó en el municipio de Caicedonia (Valle del Cauca). Las distancias de siembra fueron de 2,5 m entre surcos y 2 m entre plantas, los tratamientos fueron con y sin desbrote. El diseño experimental fue completamente al azar. La unidad experimental fue conformada por 20 plantas, con cuatro repeticiones. Las variables evaluadas fueron la altura del primer botón floral, diámetro del tallo, altura de la planta, numero de hojas y tiempo de aparición del primer botón floral. Las variables altura de la aparición del primer botón floral, el tiempo transcurrido para la aparición del primer botón y altura de la planta presentaron diferencias altamente significativas $(p<0,05)$ cuando se realizaba la poda temprana. Obteniendo un mejor comportamiento de la papaya con desbrote, con reducción de las variables en el tiempo de aparición de los botones florales (precocidad), y altura de la planta, lo que favorece el proceso de producción del cultivo.
\end{abstract}

Palabras clave: Carica papaya L., brote vegetativo, producción de flores.

\begin{abstract}
The cultivation of papaya is mainly managed based on the traditional knowledge of the farmers, because the research in physiological aspects is scarce and there is no scientific information about the effect of the early pruning in the flowering. Pruning of lateral shoots usually takes place between 55 and 70 days after transplantation, when the first floral bud emerges, losing photoasimilates in the shoots in the first few days after the transplant. The aim of the study was to evaluate the effect of early pruning at the beginning of flowering of the Tainung 1 papaya. The study was carried out in the municipality of Caicedonia (Valle del Cauca). Planting distances were $2.5 \mathrm{~m}$ between furrows and $2 \mathrm{~m}$ between plants, treatments were with and without stripping. The experimental design was completely randomized. The experimental unit consisted of 20 plants, with four replicates. The variables evaluated were the height of the first floral bud, stem diameter, plant height, number of leaves and time of appearance of the first floral bud. The variables height of the appearance of the first floral bud, the time elapsed for the appearance of the first bud and height of the plant presented highly significant differences $(p<0.05)$ when the pruning was performed early. Obtaining a better behavior of the papaya with pruning, with reduction of the variables in the time of appearance of the flower buds (precocity), and height of the plant, which favors the process of production of the crop.
\end{abstract}

Key words: Carica papaya L., vegetative bud, flower, production.

\footnotetext{
1 Ingeniero Agrónomo. Universidad de Caldas, Facultad de Ciencias Agropecuarias, Programa Ingeniería Agronómica, Manizales Caldas, Colombia.

$2^{*}$ Ph.D, Universidad de Caldas, Facultad de Ciencias Agropecuarias, Departamento de Producción Agropecuaria, Universidad de Caldas, Calle 65 № 26 -10, Apartado aéreo 275, Manizales - Caldas, Colombia. Correo electrónico alhuza@gmail.com
} 


\section{INTRODUCCIÓN}

La papaya nativa de América Central, está presente en todos los países tropicales. Hoy en día es uno de los frutos más importantes de los trópicos y también se produce comercialmente en regiones subtropicales en las latitudes 30$32^{\circ}$ norte a sur (Costa y Pacova 2003).

Es un fruto importante para la economía mundial. En 2010 la producción mundial fue de 11,2 millones de toneladas, que se cultiva en 775.689 ha; de este volumen, 51\% fue producido en América Central y del Sur (principalmente Brasil), 28\% en Asia, 21\% en África (FAO 2016).

En Colombia, el cultivo de la papaya se encuentra en el octavo lugar de la superficie plantada en comparación con otras frutas cultivadas. De acuerdo con informes de la FAO, el país produce alrededor de 176.747, 44 t de papaya por año con un rendimiento nacional de $23,16 \mathrm{t} \mathrm{ha}^{-1}$.

El cultivo de la papaya es importante por varias razones, entre las que se destaca la sostenibilidad, ya que es económicamente viable y mejora la calidad de vida del productor, al igual que su fácil manejo, producción en un corto período de tiempo, amplias zonas aptas para el cultivo y la aceptación en los mercados nacionales e internacionales (Reyes et al. 2014).

Sin embargo, en Colombia es escasa la información de investigación en aspectos fisiológicos acerca del efecto de la poda temprana en la floración en condiciones tropicales. Ahondando en la falta de criterios en el momento oportuno de la realización de las diferentes prácticas culturales de manejo del cultivo de papaya.

Entre las prácticas culturales se incluyen el desbrote, para inhibir el crecimiento de las yemas vegetativas, en el punto de inserción del peciolo de la hoja con el tallo (Landgren y Ness 2017). La práctica de desbrote es realizada empíricamente por los productores colombianos, sin saber cuál es el mejor momento para ponerlo en práctica. Por lo general se lleva a cabo entre 55 y 70 días después del trasplante en campo en el momento de emisión del primer botón floral. Así, el objetivo de este estudio fue evaluar el efecto de la poda temprana de brotes laterales al inicio de la floración de papaya Tainung 1 .

\section{MATERIALES Y MÉTODOS}

El experimento se llevó a cabo entre junio a diciembre de 2015, en el municipio de Caicedonia (Valle del Cauca), con latitud $04^{\circ}$ $21^{\prime} 49^{\prime \prime} \mathrm{N}$ y longitud $75^{\circ} 51^{\prime} 36^{\prime \prime} \mathrm{W}$, temperatura media de $25{ }^{\circ} \mathrm{C}$, humedad relativa del $75 \%$, precipitación anual de $1800 \mathrm{~mm}$ y altitud de 1100 msnm, en un suelo con textura franca.

El material de siembra fue el hibrido de papaya Tainung 1, siguiendo las recomendaciones técnicas de acuerdo con Arango et al. (2002).

En la germinación se utilizó bandejas de 50 lóculos, con sustrato Plantmax ${ }^{\circledR}$. Las plantas de semillero se mantuvieron en un invernadero hasta los 30 días, posteriormente se realizó el trasplante definitivo a campo.

Las distancias de siembra fueron de 2,0 m entre plantas y 2,5 m entre surcos, con riego por goteo a una distancia de $10 \mathrm{~cm}$ del cuello de la raíz, con un flujo de 0,6 litros minuto ${ }^{-1}$. La fertilización se realizó de acuerdo con el análisis del suelo y fue fraccionado en intervalos de 8 días, desde el trasplante hasta completar 60 días. Posteriormente se realizó la fertilización con fuentes compuestas (15-15-15) y menores granulados a cada 30 días hasta el final del ciclo $(15 \%$ de nitrógeno, potasio y fosforo, $2 \%$ de magnesio, $5 \%$ de calcio, $3 \%$ de zinc y $2 \%$ boro, al momento de la siembra).

El diseño experimental fue completamente al 
azar con dos tratamientos, T1: sin desbrote y T2: con desbrote. La unidad experimental fue de 20 plantas, con cuatro repeticiones, para un total de 80 plantas por tratamiento. Los desbrotes se realizaron semanalmente, de acuerdo a la aparición de brotes laterales antes de la floración.

Las variables evaluadas fueron: el número de días desde el trasplante hasta el momento de la emisión del primer brote floral. Después de la aparición del primer botón floral se evaluó: altura del primer botón (APB), medida desde el nivel del suelo hasta el punto de inserción del primer botón; diámetro del tallo (DT), medido a $20 \mathrm{~cm}$ por encima del nivel del suelo; altura de la planta (AP) medida desde el nivel del suelo hasta el ápice de la planta y el número de hojas por planta (NF).

Los datos obtenidos fueron analizados mediante análisis de varianza usando el programa estadístico SAS (SAS Inst. Inc. Cary, $\mathrm{NC}$ ), adicionalmente se realizaron pruebas de promedios comparativos por medio del test de Duncan a nivel de significancia del 5\%.

\section{RESULTADOS Y DISCUSIÓN}

Como se muestra en la tabla 1, el análisis de varianza arrojo diferencias significativas $(p<0,05)$ para las variables altura de inserción del primer botón floral, altura de planta, diámetro del tallo, número de hojas por planta. Hubo también una diferencia cuando se utiliza el desbrote en la papaya, en comparación con las prácticas de cultivo realizado por los agricultores en Colombia.

Tabla 1. Cuadrado medio de la altura del primer botón floral (APB), altura de la planta (AP), diámetro del tallo (DT) y el número de hojas por planta $(\mathrm{NH})$.

\begin{tabular}{lcccr}
\hline \multirow{2}{*}{ Fuente de variación } & \multicolumn{4}{c}{ Cuadrado medio } \\
\cline { 2 - 5 } & $\mathrm{APB}$ & $\mathrm{AP}$ & $\mathrm{DT}$ & $\mathrm{NH}$ \\
\hline Tratamiento & $5814,88^{*}$ & $7454,21^{*}$ & $521,645^{*}$ & $544,5^{*}$ \\
Error & 0,39 & 0,93 & 0,39 & 0,18 \\
\hline
\end{tabular}

De acuerdo con la tabla 2, se observó mayores medias para las variables altura del primer botón floral y la altura de la planta el tratamiento con desbrote. Sin embargo, las plantas sin desbrote exhibieron el mayor promedio para las variables diámetro de tallo y número de hojas por planta. Estas variables pueden expresar un mayor rendimiento del cultivo de papaya más productivos. A este respecto, se prefieren los cultivares que inician la primera floración a una altura menor, considerándose esta característica positiva, por ser más fáciles de cosechar y reducir los costos de producción (Dantas et al. 2002).

Tabla 2. Prueba de comparación múltiple para las variables altura del primer botón floral (APB), altura de planta (AP), diámetro del tallo (DT), y el número de hojas por planta $(\mathrm{NH})$ a los 180 días.

\begin{tabular}{lcccc}
\hline \multirow{2}{*}{ Fuente de variación } & \multicolumn{4}{c}{ Cuadrado medio } \\
\cline { 2 - 5 } & APB $(\mathrm{cm})$ & AP $(\mathrm{cm})$ & DT $(\mathrm{cm})$ & $\mathrm{NH}$ \\
\hline Sin desbrote & $87,87 \mathrm{a}$ & $77,76 \mathrm{a}$ & $23,24 \mathrm{a}$ & $19,14 \mathrm{a}$ \\
Con desbrote & $79,98 \mathrm{~b}$ & $71,66 \mathrm{~b}$ & $21,63 \mathrm{~b}$ & $17,49 \mathrm{~b}$ \\
\hline
\end{tabular}

La floración de papaya Tainung 1, depende de la zona agroecológica donde se siembra, del manejo de la nutrición y de otras prácticas culturales. En 55 días después de la siembra, floración se puede retrasar en regiones de clima cálidopor debajo de 1.000 msnm y la temperatura media de $26{ }^{\circ} \mathrm{C}$, llegando a un máximo de 70 días para las regiones comprendidas entre $1000-1300 \mathrm{msnm}$ y $20^{\circ} \mathrm{C}$. Sin embargo, por las condiciones de Caicedonia (Colombia), en 85 días a una altitud de 1.100 msnm y $25{ }^{\circ} \mathrm{C}$, los resultados fueron satisfactorios.

La aparición del botón floral en el cultivo de la papaya es un factor que determina el inicio de la producción del cultivo, y si la floración se produce en menos tiempo, facilitará un rápido retorno de la inversión en el cultivo (Alves 2003). De acuerdo con Alonso et al. (2008), el mejoramiento de la papaya insta a reducir la altura de la planta mediante la selección de los genotipos más pequeños y de un alto vigor. 
Los resultados observados en la tabla 3, muestran que el uso del desbrote, se obtuvo un mayor número de plantas con botón floral a los 120 días, mientras que sin desbrote el porcentaje de plantas que mostraron botón floral fue estadísticamente inferior, para las demás épocas no hubo diferencias estadísticas.

Tabla 3. Prueba de comparación múltiple para la variable emisión del botón floral en el tiempo.

\begin{tabular}{lccccc}
\hline \multirow{2}{*}{ Fuente de variación } & \multicolumn{5}{c}{$\begin{array}{c}\text { Plantas que emitieron el botón floral (\%) } \\
\text { Días después del trasplante }\end{array}$} \\
\cline { 2 - 6 } & 30 & 60 & 90 & 120 & 150 \\
\hline Sin desbrote & 0 & 0 & $42,5 \mathrm{a}$ & $85,0 \mathrm{~b}$ & $100,0 \mathrm{a}$ \\
Con desbrote & 0 & 0 & $45,0 \mathrm{a}$ & $95,0 \mathrm{a}$ & $100,0 \mathrm{a}$ \\
\hline Medias con igual letra columna no difieren por la prueba de \\
Tukey al 5\% de probabilidad.
\end{tabular}

De acuerdo con Pérez et al. (2015), con el uso de activadores fisiológicos a partir de los 80 días comienzan a aparecer los primordios florales los cuales originan a las flores. Estos mismos autores demuestran que entre los 80 y 130 días hay un pico en la formación de primordios florales en el cultivo y comienza a producirse un mayor número de estos en la medida que pasan los días, pero a partir de los 180 días no se destacan cambios sustanciales en cuanto a la formación de primordios, teniendo en cuenta que este cultivo comienza a fructificar y producir a los 9 meses. Esto evidencia una respuesta positiva al hacer el desbrote y por tanto una estimulación del desarrollo de primordios florales. A los 120 días, con el comienzo de la fructificación y a pesar de disminuir el número de primordios, se mantuvo la diferencia significativa entre los tratamientos y el testigo sin desbrote.

El diámetro del tallo mostró mejor comportamiento para las plantas que no han sido podadas a partir de los 90 días. Sin embargo, hasta los 60 días, no hubo diferencia en el desbrote o no (Tabla 4).

El aumento de diámetro del tallo se traduce en mayores reservas de nutrientes para ser trasladadas a la fruta de la planta. Como se ha señalado por Rodríguez et al. (2014), este parámetro indica, en cierto sentido (>diámetro $>$ vigor), lo que es considerado una variable positiva en la elección de un genotipo. De acuerdo con Ferreira et al. (2016), determinaron los valores del coeficiente de variación de investigaciones en el cultivo de papaya para guiar a los investigadores en la evaluación de sus estudios sobre diferentes caracteres de campo, sobresaliendo el diámetro del tallo y la altura de la inserción del primer botón floral.

Al respecto, Arrieta y Carrillo (2002), coincidieron en que el grosor del tallo es una de las variables morfológicas más correlacionadas con el rendimiento de las frutas. Pérez et al. (2015), con el uso de activadores fisiológicos observaron a los 180 días una respuesta de las aplicaciones de activadores fisiológicos

Tabla 4. Prueba de comparación múltiple para las variables diámetro del tallo $(\mathrm{cm})$ en el tiempo (días después de trasplante - DDT), altura de la planta $(\mathrm{cm})$ y número de hojas.

\begin{tabular}{lccccc}
\hline \multirow{2}{*}{ Tratamiento } & \multicolumn{5}{c}{ Diámetro del tallo $(\mathrm{cm})$} \\
\cline { 2 - 6 } & 30 DDT & 60 DDT & 90 DDT & 120 DDT & 150 DDT \\
\hline Sin poda & $13,67 \mathrm{a}$ & $17,05 \mathrm{a}$ & $22,62 \mathrm{a}$ & $29,40 \mathrm{a}$ & $33,47 \mathrm{a}$ \\
Con poda & $12,95 \mathrm{a}$ & $16,15 \mathrm{a}$ & $20,52 \mathrm{~b}$ & $27,45 \mathrm{~b}$ & $31,07 \mathrm{~b}$ \\
\hline Tratamiento & \multicolumn{5}{c}{ Altura de la planta $(\mathrm{cm})$} \\
\hline Sin poda & $52,10 \mathrm{a}$ & $62,50 \mathrm{a}$ & $78,25 \mathrm{a}$ & $93,32 \mathrm{a}$ & $102,65 \mathrm{a}$ \\
Con poda & $49,15 \mathrm{~b}$ & $60,22 \mathrm{~b}$ & $71,53 \mathrm{~b}$ & $84,10 \mathrm{~b}$ & $93,30 \mathrm{~b}$ \\
\hline Tratamiento & \multicolumn{5}{c}{ Número de hojas en el tiempo (días) } \\
\hline Sin poda & $14,00 \mathrm{a}$ & $16,90 \mathrm{a}$ & $18,60 \mathrm{a}$ & $22,85 \mathrm{a}$ & $23,35 \mathrm{a}$ \\
Con poda & $12,07 \mathrm{~b}$ & $14,92 \mathrm{~b}$ & $18,15 \mathrm{~b}$ & $20,65 \mathrm{~b}$ & $21,65 \mathrm{~b}$ \\
\hline \multicolumn{7}{c}{ Medias con igual letra columna no difieren por la prueba de Tukey al 5\% de probabilidad. } \\
\hline \multicolumn{5}{c}{}
\end{tabular}


(A-CETAS/07, obtenido a partir de residuos de la industria azucarera) a razón de 10 y $50 \mathrm{~mL}$ L-1, alcanzando valores similares, aunque si se observa una diferencia altamente significativa con relación el testigo.

Para altura de la planta, hubo plantas significativamente más altas cuando no se llevó a cabo el desbrote (Tabla 4), lo cual no es deseable porque las plantas de gran tamaño son más difíciles de llevar a cabo las prácticas culturales tales como deshoje, pulverización y cosecha.

Pereira et al. (2002) destacan que el rendimiento del cultivo está directamente influenciada por la altura. Sin embargo, las plantas muy altas no son deseables por mostrar entrenudos más largos, lo que hace difícil la cosecha y la reducción de la longevidad del cultivo. Un crecimiento continuo del tallo se manifestó a partir de los 90 días lo que se incrementa en las plantas que no presentaron desbrote hasta la última etapa del ciclo a los 150 días, donde se alcanza diferencias altamente significativas respecto al tratamiento con desbrote. Similares resultados fueron obtenidos por Pérez et al., (2015), con aplicaciones de activadores fisiológicos en el cultivo papaya.

Las plantas en las cuales se realizó el desbrote fueron $8 \mathrm{~cm}$ más bajas que las que no se desbrotaron. Sin embargo, las plantas no podadas en el momento de la emisión del primer botón floral mostraron alturas similares a las presentadas por Alonso et al. (2008). Sin embargo, los resultados de este estudio no corroboran la información mostrada por los agricultores en la región papayera de Colombia, que informan que las plantas cuando se desbrotan en la etapa de floración temprana las plantas presentan mayor altura.

Para el número de hojas, se observó diferencias significativas cuando no se realizaba el desbrote (Tabla 4).
Marín et al. (2006), evidenciaron que el diámetro de la copa y el número de hojas por planta no interfiere con la producción de brotes por planta. Contrariamente Storey (1969) y Mahouachi et al. (2005), informan que el número de hojas producidas por año se toma como base para la selección de cultivares con un mejor crecimiento vegetativo $y$, a su vez, es un claro indicador de la productividad, teniendo en cuenta que, en la axila de cada hoja se forma al menos una fruta.

Con las evaluaciones realizadas durante el ciclo, se constató que el número de hojas vario durante el periodo de evaluación, y de acuerdo con Pérez et al. (2015), la taza de emisión de hojas se incrementa entre los 900 y 150 días de trasplantadas. Al cabo de los tres meses se observó un incremento progresivo del área foliar a medida que no se realizaba el desbrote.

Pérez et al (2015), evaluando un activador fisiológico aumento la tasa de emisión de hojas en promedio de 34,4 a 38,3 respecto al testigo con 32,6 . Estas observaciones coinciden con Ramos y Farrés (2002), quienes plantean que entre los 80 y 180 días ocurre la mayor emisión foliar en el cultivo de la papaya. En este punto de máxima tasa de emisión de hojas se expresa incluso si la yema apical de la planta ejerza un dominio sobre los brotes laterales, impidiendo que las yemas laterales puedan crecer y desarrollar uniformente (Lopes et al. 2008).

De forma general, y como es descrito en otras especies frutales (Mendonça y Mendeiros, 2011), es necesario el desbrote, ya que esta eliminación de brotes laterales no productivos se desarrollan a través de las reservas a expensas de la floración y fructificación.

\section{CONCLUSIÓN}

Sobre la base de los resultados obtenidos se concluye que la poda temprana (desbrote), tuvo un efecto sustancial sobre ciertos parámetros 
importantes, es decir, la altura de la planta, la aparición de los botones florales (precocidad) y el número de flores. Poda temprana podría mejorar la precocidad en la aparición de la flor y afectando positivamente el número de flores. En este caso, se sugiere realizar más trabajos de investigación en este sentido. Sin embargo, se requiere investigación adicional, que cubra una gama de severidades de poda.

\section{REFERENCIAS}

Alonso, E., Ramos, R. y Torne, Q. 2008. Caracterización y evaluación de los recursos genéticos de papaya (Carica papaya L.). CitriFrut, 23: 21-25.

Alves, F. 2003. A cultura do mamão Carica papaya L., no mundo, no Brasil e no Estado do Espírito Santo. In: Martins, D.S. y Costa, A.F.S. A cultura do mamoeiro: tecnologias de produção. Vitória: Incaper, Cap. 1, p. 29.

Arango, L., Roman, C., Salamanca, C., Almansa, E., Bernal, J., Leon, G., Rey, V., Ariza, M. y Gomez, P. 2002. El cultivo en los Ilanos orientales de Colombia. Manual de asistencia técnica, $\mathrm{n}^{\circ} 4$. Ed. COPRPOICA, 99p.

Arrieta, R. y Carrillo, A. 2002. Response of the papaya tree variety maradol at three subsurface drainage spacing distances. Terra, Chapingo, 20(4): 435-447.

Costa, A. y Pacova, B. 2003. Caracterização de cultivares, estratégias e perspectivas do melhoramento genético do mamoeiro. In: Martins, D.S. y Costa, A.F. S. A cultura do mamoeiro: tecnologias de produção. Vitória: Incaper, Cap. 3, p. 59-102.

Dantas, L., Dantas, A. y Lima, J. 2002. Mamoeiro. In: Bruckner, C.H (Eds). Melhoramento de fruteiras tropicais, Viçosa: UFV, p. 309-349.
FAO. Faostat. 2016. Disponível em: <http:// faostat.fao.org/site/339/default.aspx>. Acesso em: 26 ago. 2016.

Ferreira, J., Schmidt, E., Schmidt, O., Cattaneo, L., Sobreira, A. y Cruz, C. 2016. Comparison of methods for classification of the coefficient of variation in papaya. Revista Ceres, 63(2): 138-144. https://doi. org/10.1590/0034-737X201663020004.

Landgren, C. y Ness, B. 2017. Plant Growth. Salem Press Encyclopedia Of Science [serial on the Internet]. [23 Abril 2017].

Lopes, J., Coelho, R., Bregonci, I., Macedo, C. y Maia, L. 2008. Brotação de mamoeiro tainung 1 submetido a diferentes alturas de corte do caule. Ciência e Agrotecnologia, 32: 360-365. https://doi.org/10.1590/ S1413-70542008000200002.

Mahouachi, J., Pio, A., Socorro, R., Regalado, C. y Rodríguez, P. 2005. Respuestas de la papaya (Carica papaya L.) frente al estrés hídrico: crecimiento vegetativo y contenido de elementos minerales. Actas Portuguesas de Horticultura, 6: 193-199.

Marin, S., Pereira, M., Amaral, J., Martelleto, L. y Ide, C. 2006. Heterosis in papaya hybrids from partial diallel of "Solo" and "Formosa" parents. Crop Breeding and Applied Biotechnology, 6: 24-29. https:// doi.org/10.12702/1984-7033.v06n01a04.

Mendonça, V. y Mendeiros, L. 2011. Importância da fruticultura, poda das árvores frutíferas, propagação das plantas frutíferas. Boletim I. Mossoró, $\mathrm{R}$

Pereira, G., Marin, L., Martelleto, P., Ide, D., Martins, P. y Pereira, S. 2002. Melhoramento genético do mamoeiro (Carica papaya L.): comportamento de híbridos no norte do Estado do Rio de Janeiro. In: XVIII Congresso Brasileiro de Fruticultura: tecnologia, competitividade, sustentabilidade, Santa Catarina, Brasil. 
Pérez, R., Hernández, I., Cosio, E. y Sanchez,

D. 2015. Nuevo activador fisiológico potencializador de la fructificación en papaya (Carica papaya L.). Revista Brasileira de Fruticultura, 37(4): 10651073. https://doi.org/10.1590/01002945-203/14.

Ramos, R. y Farrés, E. 2002. Nutrición en Papaya. In:Curso internacional de papaya, Guatemala. p.39-42.]

Reyes, P., Murillo, A., Nieto, G., Troyo, D., Reynaldo, E., Rueda, P. y Guridi, I. 2014. Humates of vermicompost as mitigator of salinity in brasil (Ocimum basilicum L.). Revista da Facultad Ciencias Agrária, 46(2): 149-162.
Rodríguez, C., Díaz, H., Pérez, G., Cruz, Z. y Rodríguez, H. 2014. Evaluation of quality and yield in papaya wild (Carica papaya L.) from Cuba. Cultivos Tropicales, San Jose' de las Lajas, 35(3): 36-44.

Storey, B. 1969. Papaya. In: Ferwerda, F.D. y Wit, F. eds., Outlines of perennial crop breeding in the tropics. Misc. Papers 4, Landbouwhogeschool, Wageningen, The Netherlands, p. 389-407. 